\title{
Functional analysis of human glucokinase gene mutations causing MODY2: exploring the regulatory mechanisms of glucokinase activity
}

\author{
C. M. García-Herrero • M. Galán • O. Vincent • \\ B. Flández • M. Gargallo • E. Delgado-Alvarez • \\ E. Blázquez $\cdot$ M. A. Navas
}

Received: 14 July 2006 / Accepted: 21 October 2006 / Published online: 21 December 2006

(C) Springer-Verlag 2006

\begin{abstract}
Aims/hypothesis Glucokinase (GCK) acts as a glucose sensor in the pancreatic beta cell and regulates insulin secretion. In the gene encoding GCK the heterozygous mutations that result in enzyme inactivation cause MODY2. Functional studies of naturally occurring $G C K$ mutations associated with hyperglycaemia provide further insight into the biochemical basis of glucose sensor regulation.

Materials and methods Identification of GCK mutations in selected MODY patients was performed by single-strand conformation polymorphism and direct sequencing. The
\end{abstract}

C. M. García-Herrero • M. Galán • E. Blázquez • M. A. Navas

Department of Biochemistry and Molecular Biology III,

Faculty of Medicine, Complutense University of Madrid,

Madrid, Spain

O. Vincent

Institute of Biomedical Research Alberto Sols-CSIC,

Madrid, Spain

B. Flández

Endocrinological Service, University Hospital of Getafe,

Getafe, Spain

M. Gargallo

Endocrinological Service, Virgen de la Torre Hospital,

Madrid, Spain

E. Delgado-Alvarez

Endocrinological Service, Hospital General de Asturias,

Oviedo, Spain

M. A. Navas $(\bowtie)$

Departamento de Bioquímica y Biología Molecular III, Facultad de Medicina, Universidad Complutense de Madrid,

Ciudad Universitaria,

28040 Madrid, Spain

e-mail: manavas@med.ucm.es kinetic parameters and thermal stability of recombinant mutant human GCK were determined, and in pull-down assays the effect of these mutations on the association of GCK with glucokinase (hexokinase 4) regulator (GCKR, also known as glucokinase regulatory protein [GKRP]) and 6-phosphofructo-2-kinase/fructose-2,6-bisphosphatase (PFKFB1, also known as PFK2) was tested.

Results We identified three novel GCK mutations: the insertion of an asparagine residue at position 161 (inserN161) and two missense mutations (M235V and R308W). We also identified a fourth mutation (R397L) reported in a previous work. Functional characterisation of these mutations revealed that insertion of asparagine residue N161 fully inactivates GCK, whereas the M235V and $\mathrm{R} 308 \mathrm{~W}$ mutations only partially impair enzymatic activity. In contrast, GCK kinetics was almost unaffected by the R397L mutation. Although none of these mutations affected the interaction of GCK with PFKFB1, we found that the $\mathrm{R} 308 \mathrm{~W}$ mutation caused protein instability and increased the strength of interaction with GCKR.

Conclusions/interpretation Our results show that different MODY2 mutations impair GCK function through different mechanisms such as enzymatic activity, protein stability and increased interaction with GCKR, helping further elucidate the regulation of GCK activity.

Keywords GCKR · GKRP· Glucokinase · Glucokinase mutation - Glucokinase regulatory protein - Glucose sensor · MODY · PFK2 - PFKFB1 - 6-Phosphofructo-2kinase/fructose-2,6-bisphosphatase

\section{Abbreviations}

BCL2 B-cell leukaemia/lymphoma 2

DUSP12 dual specificity phosphatase 12 


$\begin{array}{ll}\text { F1P } & \text { fructose 1-phosphate } \\ \text { F6P } & \text { fructose 6-phosphate } \\ \text { GCK } & \text { glucokinase } \\ \text { GCKR } & \text { glucokinase (hexokinase 4) regulator } \\ \text { GST } & \text { glutathione } S \text {-transferase } \\ K_{\text {cat }} & \text { catalytic constant } \\ K_{\mathrm{m}} & \text { Michaelis-Menten constant } \\ \text { nH } & \text { Hill coefficient } \\ \text { PFKFB1 } & \text { rat liver isoform of 6-phosphofructo-2-kinase/ } \\ & \text { fructose-2,6-bisphosphatase } \\ \text { SSCP } & \text { single-strand conformation polymorphism }\end{array}$

\section{Introduction}

MODY is a heterogeneous group of monogenic forms of diabetes mellitus characterised by autosomal dominant inheritance, an early age of onset and beta cell dysfunction [1]. The heterozygous mutations in the gene encoding glucokinase (GCK) that result in enzyme inactivation are the cause of the MODY2 subtype. MODY2 accounts for approximately $30-60 \%$ of MODY families and is characterised by a mild form of hyperglycaemia present from birth [2]. These patients are usually treated with diet alone and rarely develop diabetes-associated complications [3].

The specific MODY2 phenotype results from the impairment of GCK function. GCK plays a role as a beta cell glucose sensor by integrating blood glucose levels and glucose metabolism with insulin secretion [4-6]. This specific function of GCK is based on the particular kinetic characteristics of this enzyme, which include a low affinity for glucose, cooperativity with this substrate, and a lack of end-product inhibition at physiological concentrations. In addition, GCK activity is regulated through protein-protein interactions by the glucokinase (hexokinase 4) regulator (GCKR, also known as glucokinase regulatory protein [GKRP]), which acts as a competitive inhibitor with respect to glucose and also regulates the nucleo-cytoplasmic localisation of the enzyme [7-9]. In addition, GCK has been shown to associate with other partners, such as the bifunctional enzyme 6-phosphofructo-2-kinase/fructose2,6-bisphosphatase (PFKFB1, also known as PFK2) [10, 11], a dual specificity phosphatase [12], the neuronal isoform of nitric oxide synthase [13], the proapoptotic Bcell leukaemia/lymphoma 2 (BCL2) family member BCL2antagonist of cell death (BAD) [14] and the precursor of the propionyl-CoA carboxylase beta subunit [15]. Nevertheless, the biological significance of some of these interactions remains to be elucidated.

MODY2 mutations are located throughout the gene and most of them have negative effects on the kinetic parameters of the enzyme. These effects, which are reflected as a lower activity index, lead to an increased threshold for glucose-stimulated insulin release [16]. However, not all the $G C K$ mutations found in MODY families affect the enzymatic activity of GCK equally. Functional characterisation of about one-fourth of MODY2 mutations has shown that the molecular defects of the mutant enzyme are reflected by a modification of one or more kinetic parameters or none of them at all. These results suggest that some of these mutations affect GCK activity through other mechanisms. For example, the involvement of some of these mutations in diabetes has been proposed to be due to an effect on protein stability and/or a loss of regulation by GCKR [17-19]. However, the effects of MODY2 mutations on the interaction of GCK with other cellular partners have not been studied previously.

In this work, we report the identification and characterisation of $G C K$ mutations that co-segregate with diabetes in MODY2 families. These mutations include three novel ones: the insertion of an asparagine residue at position 161 (inserN161) and two missense mutations, R308W and M235V; we also report a fourth missense mutation, R397L, which has been reported previously [20]. Functional analysis of these mutations was carried out by measuring their effects on the kinetic parameters of the enzyme, on protein stability, and on the interaction of GCK with the associated proteins GCKR, PFKFB1 and dual specificity phosphatase 12 (DUSP12).

\section{Subjects and methods}

Subjects The diabetic patients involved in this study were referred to our laboratory for a molecular diagnosis of MODY. The probands were referred by authors of this study, as follows: probands from families P33 and P38 by B. Flández; the proband from family P35 by M. Gargallo; and the proband from family P42 by E. Delgado-Alvarez. The clinical diagnosis of MODY was made using classical criteria: impaired fasting glucose or development of diabetes before the age of 35 years; a negative search for the markers of type 1 diabetes (islet cell antibodies, GAD antibodies, tyrosine phosphatase antibodies, insulin autoantibodies); and a family history of diabetes for at least two consecutive generations. The HOMA value was calculated as (baseline insulin concentration $[\mu \mathrm{U} / \mathrm{ml}] \times$ baseline glucose concentration $[\mathrm{mmol} / 1]) / 22.5$. All families were of Spanish white descent. Informed consent was obtained from the subjects or their parents. The studies were performed according to the Declaration of Helsinki as revised in 2000 and approved by the corresponding ethical committees. 
Single-strand conformation polymorphism analysis of the GCK gene Genomic DNA was isolated from human leucocytes using standard methods [21]. PCR of the ten exons of the $G C K$ gene expressed in beta cells (GenBank accession no. AH005826) was done using previously described primer sequences [22]. Single-strand conformation polymorphism (SSCP) analysis and sequencing were performed as described [19, 23].

\section{Production of recombinant wild-type and mutant glutathione} S-transferase-glucokinase Recombinant human wild-type beta cell GCK fused to glutathione $S$-transferase (GST; to form GST-GCK) was prepared as described previously [9]. MODY-associated mutations were introduced into the GSTGCK construct by PCR using a kit (QuikChange II Site Directed Mutagenesis Kit; Stratagene, La Jolla, CA, USA). To generate the insertion of the new asparagine residue at position 161, by insertion of bases TAA at position 483 from ATG, the following oligonucleotide was used: 5'GAAGACATCGATAATAAGGGGATCCTTCTCAA CTGGACCAAG-3'. To generate missense mutations M235V, R308W and R397L the following oligonucleotides were used, respectively: 5'-CTGCAATGCCTGCTACGTA GAGGAGATGCAGAATG-3'; 5'-CGAGCTCGTGC GGCTTGTGCTGCTCTGGCTCGTGG-3'; and 5'-CGCG AGAGCCTCAGCGAGGACGTCATGCGCATCAC-3'. Constructs carrying mutations inserN161, M235V, R308W and R397L were checked by sequencing and digestion with BamHI, SnaBI, SacI and AatII, respectively. Expression, purification and storage of fusion proteins from E. coli were performed as described previously [19, 24].

Kinetics parameter Glucokinase activity was measured spectrophotometrically using an $\mathrm{NADP}^{+}$-coupled assay with glucose-6-phosphate dehydrogenase. Determination of kinetic parameters and thermal stability tests were performed as described previously [19]. Results are shown as means $\pm \mathrm{SD}$, and statistical significance was analysed by the two-tailed Student's $t$ test. $p$ values of $<0.02$ were considered statistically significant.

In vitro translation of proteins and tests for protein-protein interactions cDNAs for Gckr, Pfkfbl and DUSP12 were transcribed using T7 RNA polymerase, and transcripts were translated using the rabbit reticulocyte lysate TNT system (Promega, Madison, WI, USA) in the presence of $\left[{ }^{35} \mathrm{~S}\right]$ methionine (Amersham Biosciences, Freiburg, Germany). The cDNA for Gckr was available in the vector pGBKT7 [19]. The cDNA for the rat liver isoform of PFKFB1, cloned in the pcDNA3 vector [25], was kindly provided by R. Bartrons (Department of Physiological Sciences II, University of Barcelona, Spain). The cDNA for DUSP12 was cloned by RT-PCR from total RNA of the human-hepatoma-derived HepG2 cell line. RT-PCR was performed using an RT-PCR System (Titan One Tube; Roche Diagnostics, Mannheim, Germany) and primers DUSP12F: 5'-GGGATCCCCATGTTGGTGGCTC-3' and DUSP12R: 5'-GGGATCCTCATATTTTTCCTGTTTG-3'. The 1.1-kb amplified fragment was cloned into the BamH1 site of pGBKT7. The relative amounts of radiolabelled in vitro-translated proteins were determined by SDS-PAGE.

For pull-down experiments, equal amounts of GST, GST-GCK and mutant proteins bound to glutathioneagarose beads (Sigma-Aldrich, Steinheim, Germany) were incubated with $\left[{ }^{35} \mathrm{~S}\right]$ methionine-labelled proteins for $1 \mathrm{~h}$ at $4^{\circ} \mathrm{C}$ in the corresponding reaction buffer. The reaction buffer used to test the GCK to GCKR interaction contained $25 \mathrm{mmol} / 1$ HEPES buffer $\mathrm{pH} \mathrm{7.1,1 \textrm {mmol } /}$ $1 \mathrm{MgCl}_{2}, 25 \mathrm{mmol} / 1 \mathrm{KCl}, 1 \mathrm{mmol} / 1$ dithiothreitol, $1 \%$ Triton X-100 and Complete Protease Inhibitor (Roche Diagnostics) with either $0.5 \mathrm{mmol} / 1$ fructose 1-phosphate (F1P) plus $25 \mathrm{mmol} / 1$ glucose, or $0.5 \mathrm{mmol} / 1$ fructose 6 phosphate (F6P) plus $5 \mathrm{mmol} / \mathrm{l}$ glucose. The reaction buffer employed to test the GCK to PFKFB1 interaction contained $25 \mathrm{mmol} / 1$ HEPES buffer $\mathrm{pH} 7.4,1 \mathrm{mmol} /$ $1 \mathrm{MgCl}_{2}, 25 \mathrm{mmol} / 1 \mathrm{KCl}, 25 \mathrm{mmol} / 1$ glucose, $1 \mathrm{mmol} /$ 1 dithiothreitol, $0.1 \%$ Triton X-100 and Complete Protease Inhibitor. The reaction buffer used to test the GCK to DUSP12 interaction contained $10 \mathrm{mmol} / 1$ Tris buffer $\mathrm{pH} 8,1 \mathrm{mmol} / 1$ EDTA, $150 \mathrm{mmol} / 1 \mathrm{NaCl}, 1 \mathrm{mmol} /$ 1 dithiothreitol, $0.1 \%$ Triton X-100 and Complete Protease Inhibitor. Pellets were washed five times with the corresponding reaction buffer, and precipitates were run on SDS-PAGE.

Two-hybrid analysis The Saccharomyces cerevisiae strain used for two-hybrid studies was Y187 (MAT $\alpha$, ura3-52, his3-200, ade2-101, trp1-901, leu2-3,112, gal4 $\Delta$, met , gal80A, URA3::GAL1 $1_{\mathrm{UAS}}-G A L 1_{\mathrm{TATA}}-L a c Z$; Clontech, Mountain View, CA, USA). Standard genetic methods were used. Yeast cells were grown in synthetic dextrose minimal medium lacking appropriate supplements to maintain selection for plasmids [26]. For $\beta$-galactosidase assays, four different transformants were grown to mid-log phase in selective synthetic dextrose minimal medium. $\beta$-Galactosidase activity was assayed in permeabilised cells and expressed in Miller units [27]. Plasmids encoding a GCKR fusion protein to the Gal4 binding domain and a fusion of GCK to the Gal4 activating domain, have been described previously [19]. Plasmid encoding the GCK(R308W) mutant derivative was derived from pACTII (Clontech) by inserting a BamH1-Xho1 fragment from the corresponding GSTGCK constructs containing the mutant GCK coding sequence between the BamH1 and Xhol sites of the polylinker. 


\section{Results}

Clinical profile of the patients

Clinical profile of the patients The clinical and anthropometric data from the index patients are given in Table 1. All these patients had a clinical family history of diabetes dating back at least two consecutive generations. The patients had mild fasting hyperglycaemia, ranging from 6.5 to $7.8 \mathrm{mmol} / \mathrm{l}$. OGTT, $\mathrm{HbA}_{1 \mathrm{c}}$ and basal C-peptide values were within the normal ranges for MODY2 families. The proband of family P33 had a HOMA value of 4.9, indicating insulin resistance. She was on a diet plus metformin treatment. Her mother had had gestational diabetes without post-pregnancy treatment, and the mother's current fasting plasma glucose levels were $6.1 \mathrm{mmol} / 1$ with normal OGTT $(4.8 \mathrm{mmol} / \mathrm{l})$. None of these patients showed any chronic diabetic complications.

\section{Identification of novel MODY2 mutations}

Identification of novel MODY2 mutations The ten exons of the $G C K$ gene expressed in beta cells were scanned for mutations using SSCP on the probands from each family. Sequencing of abnormal migrating bands revealed the heterozygous mutations shown in Table 1. Duplication of three bases, TAA (cDNA positions 480-482 from ATG), produced the insertion of a new asparagine residue between GCK amino acids Asp160 and Lys161 in family P33. Point mutations in $G C K$ exons 8 and 7 resulted in novel missense GCK mutations R308W and M235V, found in families P35 and $\mathrm{P} 42$, respectively. The missense mutation $\mathrm{R} 397 \mathrm{~L}$, found in family P38, was first reported as a homozygous mutation in an Asian infant with permanent neonatal diabetes [20]. The three novel mutations co-segregated with the MODY phenotype in the available subjects in their respective families (Table 1), and were not found in 55 unrelated healthy control individuals, who showed normal conformers of SSCP compared with the probands and their affected relatives (results not shown).

Kinetic analysis of recombinant mutant glucokinases We prepared recombinant wild-type GST-GCK and mutant GST-GCK(inserN161), GST-GCK(M235V), GST-GCK (R308W) and GST-GCK(R397L) in E. coli and compared the kinetic properties of the purified GST fusion proteins (Table 2). The strongest effect on GCK activity was produced by the insertion of an asparagine residue at position 161. This mutant GCK had lost catalytic activity and its activity index corresponded to less than $0.01 \%$ of that of the wild-type. Because of the very low activity of this mutant, the kinetic data shown in Table 2 are only approximations. This mutant displayed a 20-fold lower affinity for glucose than the wild-type protein and may have lost its cooperativity for this substrate, as shown by an approximate Hill coefficient $(\mathrm{nH})$ close to 1 . The affinity for ATP also appeared to be affected, since the MichaelisMenten constant $\left(K_{\mathrm{m}}\right)$ was decreased by about $35 \%$.

In contrast to the inserN161 mutation, the missense mutation R397L had only a very small effect on enzyme kinetics in vitro. Although the activity index of the GCK (R397L) mutant protein was lower than the wild-type value, the difference is not statistically significant $(p=0.1)$, since this mutation did not appear to affect the substrate affinities, catalytic constant $\left(K_{\text {cat }}\right)$ or the $\mathrm{nH}$.

The other two missense mutations, M235V and R308W, produced a partial catalytic inactivation of GCK, with a reduction in the activity index of $55 \%$ and $71 \%$ compared with the wild-type value, respectively. The effect of the $\mathrm{M} 235 \mathrm{~V}$ mutation must have been mainly due to a decrease in $K_{\text {cat }}$, since substrate affinities and $\mathrm{nH}$ remained almost unaffected. In contrast, mutation R308W, which also produced a decrease in $K_{\text {cat }}$, had a slight but significant negative effect on the affinity for glucose. The affinity for

Table 1 Clinical characteristics of probands and MODY2 mutations

\begin{tabular}{|c|c|c|c|c|c|c|c|c|c|c|c|}
\hline Family & $\begin{array}{l}\text { Age at } \\
\text { diagnosis/ } \\
\text { actual age } \\
\text { (years) }\end{array}$ & $\begin{array}{l}\text { Patient's } \\
\text { sex }\end{array}$ & $\begin{array}{l}\text { BMI } \\
\left(\mathrm{kg} / \mathrm{m}^{2}\right)\end{array}$ & $\begin{array}{l}\text { FPG } \\
(\mathrm{mmol} / 1)\end{array}$ & $\begin{array}{l}\text { OGTT } \\
(\mathrm{mmol} / \mathrm{l})\end{array}$ & $\begin{array}{l}\mathrm{HbA}_{1 \mathrm{c}} \\
(\%)\end{array}$ & $\begin{array}{l}\text { Basal C- } \\
\text { peptide } \\
(\mathrm{ng} / \mathrm{ml})\end{array}$ & $\begin{array}{l}\text { Gene } \\
\text { exon }\end{array}$ & $\begin{array}{l}\text { Nucleotide } \\
\text { change }\end{array}$ & $\begin{array}{l}\text { Protein } \\
\text { change }\end{array}$ & $\begin{array}{l}\text { Affected } \\
\text { family } \\
\text { members }\end{array}$ \\
\hline P33 & $12 / 14$ & Female & 22 & 7.8 & 11.0 & 6.0 & 2.3 & GCK4 & $\begin{array}{l}\text { c. } 483 \\
\text { InserTAA }\end{array}$ & $\begin{array}{l}\text { Inser } \\
\mathrm{N} 161^{\mathrm{a}}\end{array}$ & $\mathrm{M}^{\mathrm{b}}, \mathrm{mGM}^{\mathrm{b}}$ \\
\hline P35 & $17 / 26$ & Female & 22 & 7.5 & 12.6 & 5.4 & 0.82 & GCK8 & c. $922 \mathrm{~A}>\mathrm{T}$ & $\mathrm{R} 308 \mathrm{~W}^{\mathrm{a}}$ & $\mathrm{S}^{\mathrm{b}}, \mathrm{F}^{\mathrm{b}}, \mathrm{pA}^{\mathrm{b}}, \mathrm{pGM}$ \\
\hline P38 & $15 / 24$ & Male & 23 & 6.5 & 8.6 & 6.5 & 1.5 & GCK9 & c. $1190 \mathrm{G}>\mathrm{T}$ & R397L & $\mathrm{F}, \mathrm{pU}$ \\
\hline P42 & $27 / 36$ & Male & 25 & 6.8 & 8.2 & 6.1 & 2.1 & GCK7 & c. $703 \mathrm{~A}>\mathrm{G}$ & $\mathrm{M} 235 \mathrm{~V}^{\mathrm{a}}$ & $\mathrm{M}^{\mathrm{b}}, \mathrm{mGM}$ \\
\hline
\end{tabular}

FPG, fasting plasma glucose; OGTT, plasma glucose 120 min after a 75-g OGTT. M, mother; S, sister; F, father; pA, paternal aunt; pU, paternal uncle; pGM, paternal grandmother; mGM, maternal grandmother.

Nucleotide numbering uses +1 as the A of the ATG initiation codon, based on the GenBank sequence no. AF041021.

${ }^{a}$ Novel mutations. ${ }^{b}$ Affected family members where mutation was checked by genotyping. 
Table 2 Kinetic constants of human recombinant wild-type and MODY2 mutant beta cell GST-GCK fusion proteins

Data represent means $\pm \mathrm{SD}$ of four separate enzyme expressions tested in duplicate. Note that the Hill coefficient $(\mathrm{nH})$ and the relative activity index $\left(\mathrm{I}_{\mathrm{a}}\right)$ are unit-less. ${ }^{\mathrm{a}} p<0.02$; ${ }^{\mathrm{b}} p=0.037$

\begin{tabular}{|c|c|c|c|c|c|c|}
\hline Preparation & $\begin{array}{l}\text { Protein } \\
\text { yield }(\mathrm{mg} / \mathrm{l})\end{array}$ & $K_{\text {cat }}\left(\mathrm{s}^{-1}\right)$ & $\begin{array}{l}S_{0.5} \text { for glucose } \\
(\mathrm{mmol} / \mathrm{l})\end{array}$ & $\mathrm{nH}$ & $\begin{array}{l}K_{\mathrm{m}} \text { for ATP } \\
(\mathrm{mmol} / \mathrm{l})\end{array}$ & $\mathrm{I}_{\mathrm{a}}$ \\
\hline $\begin{array}{l}\text { Wild-type } \\
\text { GST-GCK }\end{array}$ & $14.1 \pm 5.6$ & $55.5 \pm 8.3$ & $7.6 \pm 0.4$ & $1.42 \pm 0.03$ & $0.49 \pm 0.06$ & $1.0 \pm 0.25$ \\
\hline $\begin{array}{l}\text { GST-GCK } \\
\text { (inserN161) }\end{array}$ & $9.8 \pm 0.9$ & $0.29 \pm 0.12^{\mathrm{a}}$ & $155 \pm 29.2^{\mathrm{a}}$ & $0.99 \pm 0.017^{\mathrm{a}}$ & $0.32 \pm 0.05^{\mathrm{b}}$ & $0.0007 \pm 0.0003^{2}$ \\
\hline $\begin{array}{l}\text { GST-GCK } \\
(\mathrm{M} 235 \mathrm{~V})\end{array}$ & $9.9 \pm 1.8$ & $22.9 \pm 0.6^{\mathrm{a}}$ & $7.8 \pm 0.7$ & $1.38 \pm 0.06$ & $0.46 \pm 0.05$ & $0.45 \pm 0.08^{\mathrm{a}}$ \\
\hline $\begin{array}{r}\text { GST-GCK } \\
(\mathrm{R} 308 \mathrm{~W})\end{array}$ & $13.6 \pm 1.5$ & $22.3 \pm 2.3^{\mathrm{a}}$ & $10.7 \pm 1.0^{\mathrm{a}}$ & $1.36 \pm 0.07$ & $0.5 \pm 0.0$ & $0.29 \pm 0.04^{\mathrm{a}}$ \\
\hline $\begin{array}{l}\text { GST-GCK } \\
\text { (R397L) }\end{array}$ & $14.0 \pm 4.2$ & $42.1 \pm 3.3$ & $7.7 \pm 1.1$ & $1.5 \pm 0.05$ & $0.46 \pm 0.07$ & $0.72 \pm 0.11$ \\
\hline
\end{tabular}

the second substrate, ATP, and the $\mathrm{nH}$ were not significantly affected.

Thermolability of glucokinase mutants To test whether additional mechanisms might be involved in the inactivation of partially impaired GCK mutants, the three missense mutant proteins were subjected to an analysis of thermal stability. Since glucose has a protective effect on GCK stability and since the half-saturation constant $\left(S_{0.5}\right)$ for these mutants was almost unchanged with respect to the wild-type enzyme, we assessed the thermal stability of these mutant proteins in the presence of $50 \mathrm{mmol} / 1$ glucose. As shown in Fig. 1a, wild-type GCK activity was slightly activated after $30-\mathrm{min}$ incubation at temperatures up to $50^{\circ} \mathrm{C}$ but fell at $52^{\circ} \mathrm{C}$. The activity of all three GCK mutants, M235V, R308W and R397L, also increased for temperatures up to $42^{\circ} \mathrm{C}$, but was significantly reduced when the temperature reached $50^{\circ} \mathrm{C}$. These results indicate that all three mutations have some effect on the stability of the protein. The time-course analysis of thermal inactivation (Fig. 1b) indicates that the R308W mutation produces the strongest effect on protein stability and that $70 \%$ of GCK activity is lost within the first $15 \mathrm{~min}$ of incubation at $50^{\circ} \mathrm{C}$. The $\mathrm{GCK}(\mathrm{R} 397 \mathrm{~L})$ mutant was more stable, since $50 \%$ inactivation was observed after $30 \mathrm{~min}$ at $50^{\circ} \mathrm{C}$. In contrast, the GCK(M235V) mutant was almost unaffected over the first $15 \mathrm{~min}$ of incubation at $50^{\circ} \mathrm{C}$ and more than $50 \%$ activity was still detected after $30 \mathrm{~min}$ at this temperature.

Effect of glucokinase mutations on the interaction with associated proteins

The possible effect of these mutations on the interaction of GCK with associated proteins was also investigated. Pulldown experiments were performed to test the interaction of GCK and the corresponding mutants with GCKR, the bifunctional enzyme PFKFB1, and the dual phosphatase DUSP12. As shown in Fig. 2a, none of these mutations appeared to affect the interaction of GCK with the bifunctional enzyme. Unexpectedly, the very weak in vitro binding of GCK to DUSP12 proved to be non-specific in our pull-down experiments (Fig. 2a). In addition, we failed to detect this interaction in the two-hybrid system in yeast (data not shown). Interestingly, the strength of the interaction of GCK with GCKR in pull-down assays was specifically increased by mutation R308W, but was not affected by the other three mutations (Fig. 2). Since the interaction of GCK with GCKR has been shown to be potentiated by F6P and counteracted by F1P [7], we tested the effect of the mutation $\mathrm{R} 308 \mathrm{~W}$ in the presence of either F1P plus high glucose or F6P plus low glucose in the buffer. Increased interaction of GCKR with the GCK (R308W) mutant was observed in both of the two conditions, although it was slightly better detectable when F1P plus high glucose was present in the buffer (Fig. 2b). To provide supporting evidence that mutation R308W affects the interaction between GCK and GCKR, we tested its effect in yeast two-hybrid assays. Our results showed that GCK mutation R308W induced a significantly stronger two-hybrid interaction between these two proteins (Fig. 2c).
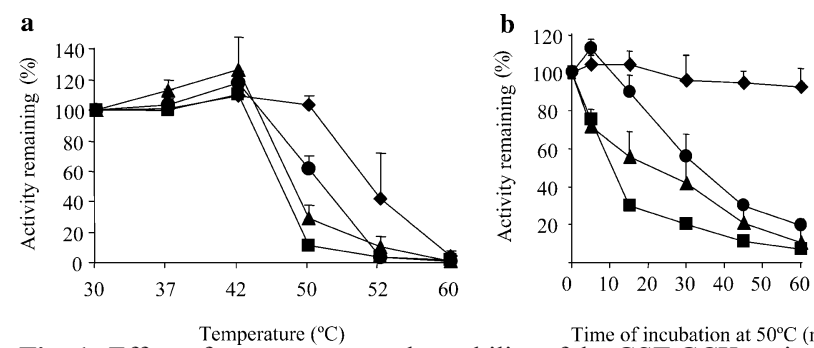

Fig. 1 Effect of temperature on the stability of the GST-GCK variants. Stock enzyme solutions were diluted to $250 \mu \mathrm{g} / \mathrm{ml}$ in storage buffer containing $30 \%$ glycerol, $50 \mathrm{mmol} / 1$ glucose, $10 \mathrm{mmol} / 1$ glutathione, $5 \mathrm{mmol} / \mathrm{l}$ dithiothreitol, $200 \mathrm{mmol} / \mathrm{l} \mathrm{KCl}$ and $50 \mathrm{mmol} / \mathrm{l} \mathrm{Tris} / \mathrm{HCl}, \mathrm{pH}$ 8.0. a The enzyme solutions were incubated for $30 \mathrm{~min}$ at different temperatures ranging from 30 to $55^{\circ} \mathrm{C}$ and then assayed at $30^{\circ} \mathrm{C}$ as described in Materials and methods. b The enzyme solutions were incubated for different periods of time from 5 to $60 \mathrm{~min}$ at $50^{\circ} \mathrm{C}$. Rhombus, GST-GCK; circle, GST-GCK(M235V); triangle, GST-GCK (R397L); square, GST-GCK(R308W). Means and SD of three independent enzyme preparations are shown for each case 


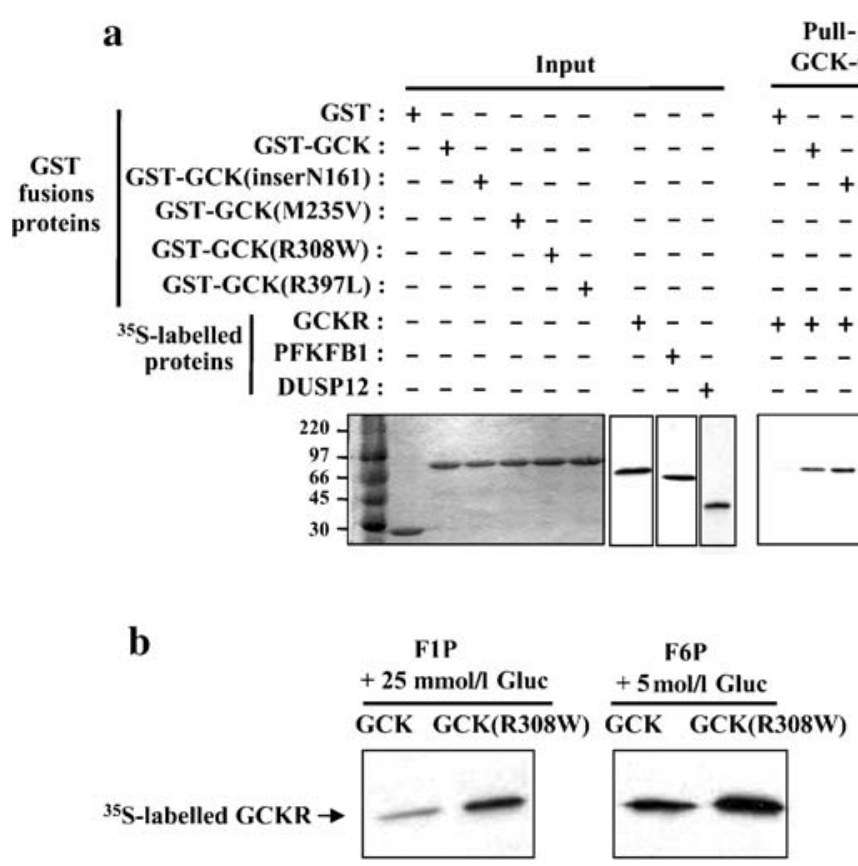

Fig. 2 Interaction of GCK and mutant derivatives with GCK-associated proteins. a In vitro binding of GCK to GCKR, PFKFB1 and DUSP12. GST-GCK wild-type or variants were immobilised on glutathioneagarose beads and incubated with in-vitro-synthesised ${ }^{35} \mathrm{~S}$-labelled GCKR, ${ }^{35}$ S-labelled PFKFB1 and ${ }^{35}$ S-labelled DUSP12. Buffer conditions, see Materials and methods section. Pull-down of GCKR was performed in the presence of $0.5 \mathrm{mmol} / \mathrm{F} 1 \mathrm{P}$ plus $25 \mathrm{mmol} / 1$ glucose. Pulled-down proteins were electrophoresed on 10\% SDS-PAGE and detected by autoradiography. Input: purified GST fusion proteins (Coomassie) or ${ }^{35} \mathrm{~S}$-labelled proteins (autoradiography) used for binding experiments $(25,10$ and $5 \%$ of the total used in the reaction mix for GCKR, PFKFB1 and DUSP12, respectively). A representative experiment from four independent assays performed for GCKR, three

Together, these results indicate that residue R308 is involved in the interaction of GCK with the regulatory protein.

\section{Discussion}

In this paper we report the genetic identification and functional characterisation of four $G C K$ mutations found to cause MODY2 in the respective families. Three of these mutations are novel (inserN161, M235V and R308W), and one (R397L) had been identified previously in an Asian infant with permanent neonatal diabetes mellitus [20]. The novel mutations inserN161, M235V and R308W cosegregated with diabetes or impaired glucose tolerance in their respective families and were not found in over 100 chromosomes from non-diabetic control subjects.

The functional characterisation of these MODY2 mutations has uncovered different defects affecting GCK function. The inserN161 mutation fully inactivates the enzyme, while all three missense mutations produced milder kinetic effects. Furthermore, the enzymatic activity

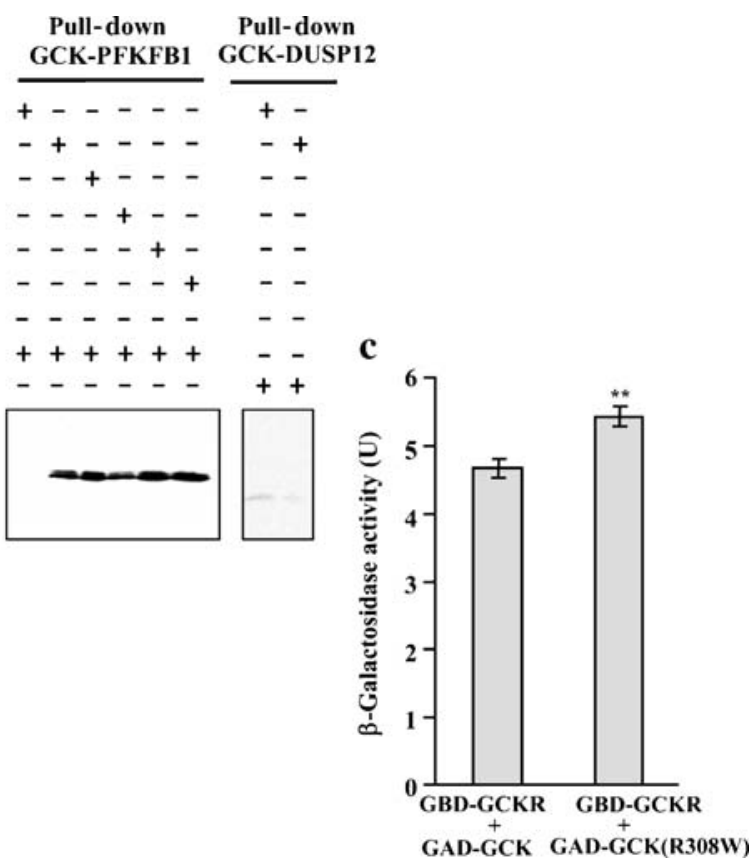

for PFKFB1 and two for DUSP12 is shown. b Comparison of the in vitro binding of GCKR to $\operatorname{GCK}(\mathrm{R} 308 \mathrm{~W})$ in the presence of fructose1-phosphate (F1P) plus high glucose or F6P plus low glucose. Pulldown assays were processed in parallel in the presence of $0.5 \mathrm{mmol} /$ $1 \mathrm{~F} 1 \mathrm{P}$ plus $25 \mathrm{mmol} / 1$ glucose or of $0.5 \mathrm{mmol} / 1 \mathrm{~F} 6 \mathrm{P}$ plus $5 \mathrm{mmol} /$ 1 glucose. Representative experiment from three independent assays. $\mathbf{c}$ Two-hybrid interaction of GCKR with GCK or GCK(R308W) mutant. Yeast strain Y187 was used, and fusion proteins were expressed from pGBKT7 and pACTII derivatives. Values are means \pm SD from $\beta$ galactosidase activity of four independent transformants. ${ }^{*} p=0.0004$. In control experiments, GBD-GCKR did not interact with Gal4 activating domain (GAD) and GAD-GCK did not interact with Gal4 binding domain (GBD) [19]

of the protein carrying mutation R397L was almost normal in comparison with the wild-type GCK. Despite these kinetic differences, the clinical profile of the patients and the absence of diabetic complications match the MODY2 phenotype. Patient P33, carrying mutation inserN161, showed some degree of insulin resistance, which is not a common characteristic of MODY patients. However, the decreased insulin sensitivity was probably unrelated to the GCK mutation, since her mother, who carries the same mutation, has a much milder phenotype. InserN161 is the second reported MODY2 mutation resulting in the insertion of one extra amino acid in GCK. Previous work revealed that the insertion of an alanine residue at position 454 in the allosteric activator site of GCK activated the enzyme [6]. The novel mutation found in family P33 resulted in the insertion of an asparagine residue between aspartic acid 160 and lysine 161, in the $\beta 7$ strand, located in the middle of the small domain of GCK (Fig. 3). The complete loss of enzymatic activity in this mutant suggests that this beta strand would be directly involved in the active site of GCK, which is consistent with its localisation in the structural model for beta cell GCK, and with previous studies 


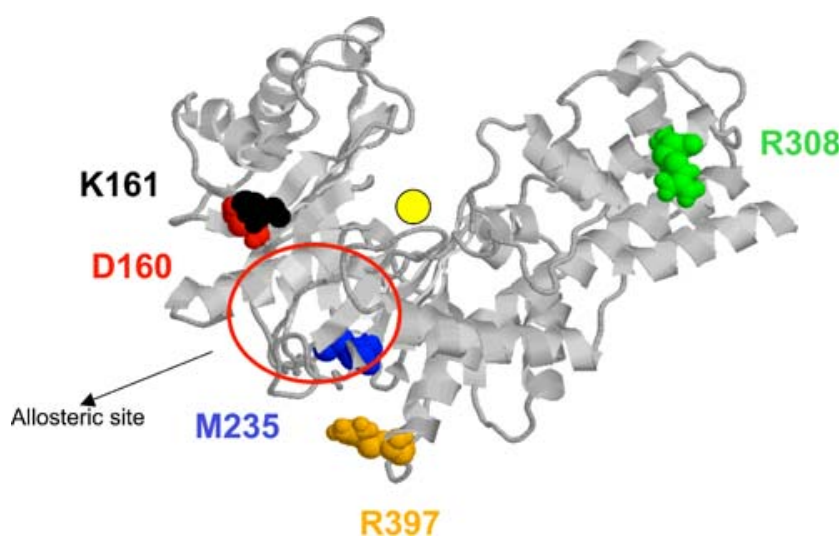

Fig. 3 Localisation of residues D160, K161, M235, R308 and R397 on the structural model for beta cell GCK. The closed conformation (1V4S) of wild-type GCK [30] is represented using the RasMol program [36]. Selected residues are indicated as clusters of coloured balls. Yellow sphere, position of glucose; red circle, allosteric site

showing that mutations of other residues in the same beta strand impair GCK activity [19, 28].

All three missense mutations are located in more external regions of the enzyme (Fig. 3) and only partially impair GCK kinetics in vitro. The M235 residue is located on the $\beta-10$ strand in the large domain of GCK. Enzymatic assays revealed that the $\mathrm{M} 235 \mathrm{~V}$ mutation resulted in a significant decrease in $K_{\text {cat }}$ without affecting substrate affinities. A similar effect on $K_{\text {cat }}$ has been described for a MODY2 mutation found in an Italian family, affecting the same residue (M235T) [29]. However, and in contrast to $\mathrm{M} 235 \mathrm{~V}, \mathrm{M} 235 \mathrm{~T}$ also resulted in a decrease in the $K_{\mathrm{m}}$ for ATP and in the affinity for glucose. Interestingly, the crystal structure of GCK complexed with a GCK allosteric activator indicates that the M235 residue, together with residues V62, I159, M210, I211 and V452, is involved in hydrophobic interactions with this compound [30]. As expected from this model, MODY2 mutations V62M and M210K result in a loss of effect of GCK activators as well as a loss of inhibition by GCKR [18, 31]. It has been proposed that these effects could be responsible for the development of hyperglycaemia. However, our results suggest that the hyperglycaemia associated with mutation $\mathrm{M} 235 \mathrm{~V}$ is probably not related to an effect on the physical interaction of GCK with GCKR.

Mutation R397L was previously identified in an Asian infant with permanent neonatal diabetes [20]. This child had a milder phenotype than other permanent neonatal diabetes-GCK patients, suggesting to those authors that this mutation may cause a less severe kinetic defect than the previously reported mutations. The R397 residue is conserved in GCKs across species but not in hexokinases. Our functional study indicates that the R397L mutation has almost no effects on GCK kinetics. Although we found some effect of this mutation on the thermal stability of the enzyme, these effects were relatively mild and not as pronounced as those induced by mutation $\mathrm{R} 308 \mathrm{~W}$ or previously described mutations such as E265K, E300K or S263P $[17,19,31]$. It is possible that this mild thermal lability alone might not be sufficient to account for the hyperglycaemia observed in the patients. Loss of regulation by GCKR and allosteric activators has been reported for other GCK mutants with increased or nearly-normal enzyme activity [18, 31]. Despite this, we found that the R397L mutation did not affect GCK-GCKR binding in vitro and was not located in the allosteric site predicted from the crystal structure [30]. A possible effect of this mutation on the interaction of GCK with other intracellular partners has been investigated. Among others, it has been reported that rat liver GCK interacts with a cytosolic dual phosphatase [12]. This phosphatase is $90 \%$ and $82 \%$ identical with mouse and human DUSP12, respectively and has been shown to increase GCK activity in vitro in a dose-dependent manner. Surprisingly, we failed to detect a physical interaction between human islet GCK and human DUSP12 in pull-down experiments and in yeast two-hybrid assays. This discrepancy between our results and previous findings could be related to the different origin of these proteins (rat and human). In addition to DUSP12, PFKFB1 has previously been shown to interact with GCK in yeast two-hybrid assays [10] and a physiological role for this interaction was reported in pancreatic beta cells and hepatocytes $[11,32]$. We confirmed the interaction of GCK with PFKFB1 in pull-down experiments. However, the R397L mutation, as well as the other mutations studied here, did not appear to affect the binding of GCK to PFKFB1, suggesting that these residues are not involved in the interaction between these two proteins.

Mutation R308W affects the kinetics and protein stability of GCK, as well as its interaction with GCKR. Residue R308 (K308 in rodent GCK) is located in the $\alpha 8$ helix, in the large domain of GCK (Fig. 3). Although this residue is distant from the active site in the structural model for GCK (Fig. 3), our results showed that the R308W mutation had significant effects on both $K_{\text {cat }}$ and affinity for glucose. Previous studies have reported that another MODY2 mutation in a contiguous amino acid (L309P) results in a similar negative effect on $K_{\text {cat }}$ and on substrate affinities [16, 33]. Thus, this result further supports the idea that this region of the protein could be involved in the affinity of the enzyme for glucose. The molecular mechanisms responsible for this kinetic defect could be related to a structural change resulting from this mutation. Indeed, our results indicate that the R308W mutation causes thermal instability in the protein. Most interestingly, we found that this mutation increased the strength of interaction between GCK and GCKR in both pull-down and two-hybrid assays. Different studies have 
been performed to identify the regions of GCK involved in interaction with GCK $[8,34,35]$. Residue R308 is located in a region that is involved in both GCKR binding and the nuclear export signal $[8,35]$. In particular, the basic-tohydrophobic L309R amino acid substitution has been shown to impair the interaction of GCK with GCKR in yeast two-hybrid assays [35]. In contrast, we found that the hydrophobic-to-basic substitution of the contiguous amino acid (R308W) reinforced the physical interaction with GCKR, providing further support that this region plays an important role in GCKR binding. The binding of GCKR to GCK is responsible for the inhibition and translocation of the enzyme into the nucleus. Although the physiological importance of GCK regulation by GCKR has been known for sometime, only a few MODY2 mutations have been reported to affect this regulation [18, $28,31]$. However, and contrary to what might be expected a priori, most of those mutations reduced GCK inhibition by the regulatory protein. Only one mutation (V182M), studied in kinetic assays, appeared to increase the sensitivity of GCK to the inhibitory effect produced by the regulatory protein [28]. R308W is the first MODY2 mutation in which an increase in the physical interaction of GCK with GCKR has been demonstrated. An increased association of GCKR to the mutant GCK might result in the inhibition of enzymatic activity and mislocalisation of the protein. This effect, together with the kinetic and stability defects produced by this mutation, would result in an even lower GCK activity in vivo. Taking into account the important role of GCKR in the regulation of hepatic GCK activity, a significant liver defect, in addition to the beta cell defect, might contribute to the higher blood glucose levels detected in the MODY2 patient P35.

In sum, we have identified $G C K$ mutations causing MODY2 in diabetic families. Although the pathophysiological consequences are similar, the biochemical defects caused by these mutations are uneven and range from full kinetic inactivation to almost normal activity. Moreover, our study has allowed the identification of the first MODY2 mutation resulting in a stronger physical interaction with GCKR, further supporting the important role of this regulatory protein in the regulation of GCK activity in vivo.

Acknowledgements We thank R. Bartrons (University of Barcelona) for providing the cDNA for rat liver PFKFB1 and P. Morales (Hospital 12 de Octubre, Madrid) for providing the DNA samples of the healthy control individuals. This work was supported by the Instituto de Salud Carlos III grant PI030203 to M. A. Navas. M. Galán was supported by a predoctoral FPU fellowship from the Comunidad Autónoma de Madrid. M. A. Navas is a Ramón y Cajal researcher of the Spanish Ministry of Education and Science.

Duality of interest The authors are not aware of any duality of interest.

\section{References}

1. Fajans SS, Bell GI, Polonsky KS (2001) Molecular mechanisms and clinical pathophysiology of maturity-onset diabetes of the young. N Engl J Med 345:971-980

2. Prisco F, Iafusco D, Franzese A, Sulli N, Barbetti F (2000) MODY 2 presenting as neonatal hyperglycaemia: a need to reshape the definition of "neonatal diabetes"? Diabetologia 43:1331-1332

3. Pearson ER, Velho G, Clark P et al (2001) Beta-cell genes and diabetes: quantitative and qualitative differences in the pathophysiology of hepatic nuclear factor-1alpha and glucokinase mutations. Diabetes 50:S101-S107

4. Matschinsky FM (1990) Glucokinase as glucose sensor and metabolic signal generator in pancreatic beta-cells and hepatocytes. Diabetes 39:647-652

5. Zelent D, Najafi H, Odili S et al (2005) Glucokinase and glucose homeostasis: proven concepts and new ideas. Biochem Soc Trans 33:306-310

6. Matschinsky FM (2005) Glucokinase, glucose homeostasis, and diabetes mellitus. Curr Diab Rep 5:171-176

7. Van Schaftingen E, Detheux M, Veiga da Cunha M (1994) Shortterm control of glucokinase activity: role of a regulatory protein. FASEB J 8:414-419

8. Shiota C, Coffey J, Grimsby J, Grippo JF, Magnuson MA (1999) Nuclear import of hepatic glucokinase depends upon glucokinase regulatory protein, whereas export is due to a nuclear export signal sequence in glucokinase. J Biol Chem 274:37125-37130

9. Alvarez E, Roncero I, Chowen JA, Vazquez P, Blazquez E (2002) Evidence that glucokinase regulatory protein is expressed and interacts with glucokinase in rat brain. J Neurochem 80:45-53

10. Baltrusch S, Lenzen S, Okar DA, Lange AJ, Tiedge M (2001) Characterization of glucokinase-binding protein epitopes by a phage-displayed peptide library. Identification of 6-phosphofructo-2-kinase/fructose-2,6-bisphosphatase as a novel interaction partner. J Biol Chem 276:43915-43923

11. Massa L, Baltrusch S, Okar DA, Lange AJ, Lenzen S, Tiedge M (2004) Interaction of 6-phosphofructo-2-kinase/fructose-2,6bisphosphatase (PFK-2/FBPase-2) with glucokinase activates glucose phosphorylation and glucose metabolism in insulinproducing cells. Diabetes 53:1020-1029

12. Munoz-Alonso MJ, Guillemain G, Kassis N, Girard J, Burnol AF, Leturque A (2000) A novel cytosolic dual specificity phosphatase, interacting with glucokinase, increases glucose phosphorylation rate. J Biol Chem 275:32406-32412

13. Rizzo MA, Piston DW (2003) Regulation of \{beta\} cell glucokinase by S-nitrosylation and association with nitric oxide synthase. J Cell Biol 161:243-248

14. Danial NN, Gramm CF, Scorrano L et al (2003) BAD and glucokinase reside in a mitochondrial complex that integrates glycolysis and apoptosis. Nature 424:952-956

15. Shiraishi A, Yamada Y, Tsuura Y et al (2001) A novel glucokinase regulator in pancreatic beta cells precursor of propionyl-CoA carboxylase beta subunit interacts with glucokinase and augments its activity. J Biol Chem 276:2325-2328

16. Davis EA, Cuesta-Munoz A, Raoul M et al (1999) Mutants of glucokinase cause hypoglycaemia- and hyperglycaemia syndromes and their analysis illuminates fundamental quantitative concepts of glucose homeostasis. Diabetologia 42:1175-1186

17. Kesavan P, Wang L, Davis E et al (1997) Structural instability of mutant beta-cell glucokinase: implications for the molecular pathogenesis of maturity-onset diabetes of the young (type-2). Biochem J 322:57-63

18. Gloyn AL, Odili S, Zelent D et al (2005) Insights into the structure and regulation of glucokinase from a novel mutation 
(V62M), which causes maturity-onset diabetes of the young. J Biol Chem 280:14105-14113

19. Galan M, Vincent O, Roncero I et al (2006) Effects of novel maturity-onset diabetes of the young (MODY)-associated mutations on glucokinase activity and protein stability. Biochem J 393:389-396

20. Porter JR, Shaw NJ, Barrett TG, Hattersley AT, Ellard S, Gloyn AL (2005) Permanent neonatal diabetes in an Asian infant. J Pediatr 146:131-133

21. Miller SA, Dykes DD, Polesky HF (1988) A simple salting out procedure for extracting DNA from human nucleated cells. Nucleic Acids Res 16:1215

22. Stoffel M, Froguel P, Takeda J et al (1992) Human glucokinase gene: isolation, characterization, and identification of two missense mutations linked to early-onset non-insulin-dependent (type 2) diabetes mellitus. Proc Natl Acad Sci USA 89:7698-7702

23. Navas MA, Vaisse C, Boger S, Heimesaat M, Kollee LA, Stoffel M (2000) The human HNF-3 genes: cloning, partial sequence and mutation screening in patients with impaired glucose homeostasis. Hum Hered 50:370-381

24. Liang Y, Kesavan P, Wang LQ et al (1995) Variable effects of maturity-onset-diabetes-of-youth (MODY)-associated glucokinase mutations on substrate interactions and stability of the enzyme. Biochem J 309:167-173

25. Perez JX, Roig T, Manzano A et al (2000) Overexpression of fructose 2,6-bisphosphatase decreases glycolysis and delays cell cycle progression. Am J Physiol Cell Physiol 279:C1359-C1365

26. Rose MD, Winston F, Hieter P (1990) Methods in yeast genetics: a laboratory course manual. Cold Spring Harbor Laboratory, Cold Spring Harbor, NY

27. Miller JH (1972) Experiments in molecular genetics. Cold Spring Harbour Laboratory, Cold Spring Harbor, NY

28. Veiga-da-Cunha M, Xu LZ, Lee YH, Marotta D, Pilkis SJ, Van Schaftingen E (1996) Effect of mutations on the sensitivity of human beta-cell glucokinase to liver regulatory protein. Diabetologia 39:1173-1179

29. Gloyn AL, Odili S, Buetter C, Njolstad PR, Shiota C, Magnuson MA, Matschinsky FM (2004) Glucokinase and the regulation of blood sugar. A mathematical model predicts the threshold for glucose stimulated insulin release for GCK gene mutations that cause hyper- and hypoglycemia. In: Matschinsky FM, Magnuson MA (eds) Glucokinase and glycemic disease: from basics to novel therapeutics. Front. Diabetes. Vol 16, Karger, Basel, Switzerland, pp 92-109

30. Kamata K, Mitsuya M, Nishimura T, Eiki J, Nagata Y (2004) Structural basis for allosteric regulation of the monomeric allosteric enzyme human glucokinase. Structure 12:429-438

31. Sagen JV, Odili S, Bjorkhaug L et al (2006) From clinicogenetic studies of maturity-onset diabetes of the young to unraveling complex mechanisms of glucokinase regulation. Diabetes 55:1713-1722

32. Payne VA, Arden C, Wu C, Lange AJ, Agius L (2005) Dual role of phosphofructokinase-2/fructose bisphosphatase-2 in regulating the compartmentation and expression of glucokinase in hepatocytes. Diabetes 54:1949-1957

33. Gidh-Jain M, Takeda J, Xu LZ et al (1993) Glucokinase mutations associated with non-insulin-dependent (type 2) diabetes mellitus have decreased enzymatic activity: implications for structure/ function relationships. Proc Natl Acad Sci USA 90:1932-1936

34. Veiga-da-Cunha M, Courtois S, Michel A, Gosselain E, Van Schaftingen E (1996) Amino acid conservation in animal glucokinases. J Biol Chem 271:6292-6297

35. Baltrusch S, Francini F, Lenzen S, Tiedge M (2005) Interaction of glucokinase with the liver regulatory protein is conferred by leucine-asparagine motifs of the enzyme. Diabetes 54:28292837

36. Sayle RA, Milner-White EJ (1995) RASMOL: biomolecular graphics for all. Trends Biochem Sci 20:374-376 